www.jmscr.igmpublication.org

Impact Factor 5.84

Index Copernicus Value: 71.58

ISSN (e)-2347-176x ISSN (p) 2455-0450

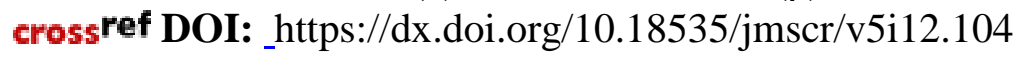

Journal Of Medical Science And Clinical Research

IGM Publication

An Official Publication of IGM Publication

\title{
Comparative Study between Universal Interlocking Nailing and Locking DCP in Tibial Diaphyseal Fractures in KMC
}

\author{
Authors \\ Dr Shanawaz Hussain ${ }^{1}$, Dr Vishal Prakash ${ }^{2}$, Dr Ajay Kumar Mahto ${ }^{3}$, \\ Dr Masroor Alam ${ }^{4}$ \\ ${ }^{1,2}$ Junior Resident, Department of Orthopaedics, KMCH, Katihar \\ ${ }^{3} \mathrm{Head}$ of the Department, Orthopaedics, KMCH, Katihar \\ ${ }^{4}$ Associate Professor, Department of Orthopaedics, KMCH, Katihar
}

\begin{abstract}
Introduction: In this modern era of industrialization and mechanization high speed traffic accidents fractures of the tibial shaft are common injuries among the long bones and mainly affect young adults, i.e. individuals at their peak of physical and work capacity. Due to their frequency, topography, mode of injury and sometimes type of treatment, they have become a major source of temporary and permanent disability. In spite of all the advances, fractures of the tibia still pose a challenge to the orthopedic surgeon as non-union and infections are quite common. The optimum management of tibial shaft fracture is not controversial now a days due to advanced techniques like interlocking. Before going into details of different modalities of treatment of tibial shaft fractures, it is necessary to be conversant with the anatomy and the blood supply of the bone.

Material and Methods: The present study was include 60 patients of fracture of tibia who were be admitted in outdoor/emergency in the department of orthopaedics over a period of 2016-2017 in Katihar Medical College.

Type of study: Prospective study

Inclusion Criteria

Patients with tibial diaphyseal fracture fulfilling the following criteria:

1 Tibial diaphyseal fracture.

2 Skin condition of the operative field Normal.

3 Patients and Party agreeing to have a surgery (after counseling).

4 No neurological deficit.

Exclusion Criteria are as follows

1. Tibial mal-alignment and shortening.

2. Range of knee motion and extensor lag.

3. Range of ankle motion.

4. Foot Motion.

5. Pain in limb.

6. Swelling.

Duration of the study: 2016 - 2017

Methods: A sequence of methods to be used during this study are as follows:

Selection of cases.
\end{abstract}


Based on Medical History (Name, Age, Sex, History with duration of pain and tenderness, history of trauma, history of any pathology etc.)

Examination of diaphyseal tibial fracture: (Gustillo \& Anderson method)

To examine attitude, deformity, swelling, tenderness etc.

Relevant laboratory investigation.

Complete Blood count, Haemoglobin estimation, Fasting \& Post Prandial Blood Sugar, Blood Urea, Serum Creatinine, bleeding Time, Clotting Time, HIV, HBsAg, Anti HCV etc.

\section{Radiological Study}

Plane X-ray of Knee with Ankle of Affected Limb (AP \& Lat view)

All the patients selected will then be operated and followed-up after 3 weeks, 5 weeks for at least 6 month with clinical and radiological assessment at each visit. In all the cases a preoperative and post-operative neurological charts will be maintained with regular assessment for proper postoperative recovery assessment.

Implants: Universal Interamedullary Interlocking Nail DCP Plate

Result: The results are assessed on the basis of Alho and Ekeland criteria's (Clinical Orthopaedics (231), 205-15 1988). ${ }^{92}$

This, criteria considers six aspects:

1) Tibial mal-alignment and shortening

2) Range of knee motion and extensor lag

3) Range of ankle motion

4) Foot Motion

5) Pain in limb

6) Swelling

Summary: The present study consisted of 60 patients with fracture shaft of tibia treated at Katihar medical college katihar, Of these 30 patients were treated by DCP and 30 patients with Interlock nailing and results were compared.

The age of patients ranged from 18-63 years with mean age of 34.07 years. The mean age in DCP group was 36.3 years and of interlock nailing group was 31.87 years.

Majority of patients (81.67\%) were males.

Conclusion: We conclude that DCP is a better mode of fixation for proximal and distal tibial facture and interlock nailing is ideal implant in diaphysial and segmental fractures.

\section{Introduction}

In this modern era of industrialization and mechanization high speed traffic accidents fractures of the tibial shaft are common injuries among the long bones and mainly affect young adults, i.e. individuals at their peak of physical and work capacity. Due to their frequency, topography, mode of injury and sometimes type of treatment, they have become a major source of temporary and permanent disability. In spite of all the advances, fractures of the tibia still pose a challenge to the orthopedic surgeon as non-union and infections are quite common. The optimum management of tibial shaft fracture is not controversial now a days due to advanced techniques like interlocking. Before going into details of different modalities of treatment of tibial shaft fractures, it is necessary to be conversant with the anatomy and the blood supply of the bone.

Nelson and many other investigators have studied the problem of vascular supply of long bones. They generally conclude that 3 main systems of vessels supply long bones.
a. The Epiphysial-metaphyseal
b. The Nutrient
c. The Periosteal

These systems are closely interrelated in their distribution. Internal fixation where indicated, either intramedullary or extramedullary, provides excellent method of treatment with good anatomical and functional results.

Plating allows an anatomical reconstruction of the bone, maintains mechanical stability and re- 
establishes endosteal vascular continuity. When compression plating or interlocking nail is used active exercises can be started early and ultimate union is quickened. This reduces the morbidity period considerably. The main dis-advantage reported with plating has been skin necrosis with resultant infection and restricted weight bearing. Earlier in the present century, surgeons applied plates merely to fix two bone fragments in approximate alignment. Mechanical failures were frequent owing to metal reaction as well as to inadequate design of screws and plates. Use of inter fragmentory compression by applying plates under tension along the longitudinal axis of the bone was reported by Danis. The concept was further explored and perfected by Muller and Allgower. The Dynamic Compression Plate (DCP) enabled a congruent fit between the screw and plate hole at different angles of inclination and has proved successful in achieving axial compression.

Intramedullary nailing popularized by Kuntscher for shaft fractures of the lower extremities has proven its value. The appeal of intramedullary techniques derives from the perception of the surgeon of ease of surgical techniques, protection of soft tissue envelop of the tibia and early weight bearing. With the introduction of reaming, indications for intramedullary nailing were greatly extended.

Fixation with multiple intramedullary pins was advocated on the premise that stacking of multiple curved pins exerts a spring force to resist angulations and rotation. The pins rely on cortical contact and continuity for axial stability. Although they had all the advantages of unreamed nailing, they had the disadvantage that they could not be used in the treatment of comminuted fractures as there tends to be shortening and displacement of such fractures. Another problem was the high incidence of non- union.

Intramedullary fracture fixation serves to stabilize fracture fragments and maintains alignment of fragments along the shaft axis, while permitting physiological micro-movement at the fracture site during functional activities. Acting as an internal splint, the implant serves as load-sharing device substituting for fracture bone, absorbs the rotational and lateral bending forces that occur during motion and weight bearing and fracture healing progresses with the formation of peripheral callus. By allowing motion of adjacent joints, rehabilitation is concurrent with treatment and 'stress-shielding' is thought to be minimal using these techniques (Tarr and Wiss, 1986). Introduction of interlocking nailing has further widened the scope of closed intramedullary nailing. Dynamic locking refers to the placement of transfixing screw only in the shorter fragment which is susceptible to rotational instability and allows intermittent compression at the fracture site during early weight bearing. Dynamic fixation is used typically in fracture of upper or lower-third of the shaft in the absence of comminution.

When the fracture is comminuted or unstable to compressive or rotational forces, interlocking screws must be placed above and the below the fracture i.e. static locking to maintain length of bone. Shortening and malrotation are controlled by transferring the axial and rotational stresses through nail rather than through the fracture Site.

\section{Aims and Objectives}

1) To evaluate the results of Interlocking Nailing vs. plating in Diaphysial fracture

2) Results of the stabilization.

3) Time taken in the union of Diaphysial fracture : Interlocking nail vs plating.

4) Stability of the Implants.

5) Blood Loss during Operation.

6) Age Distribution of the patient.

7) Comparison between Universal Interlocking nail vs DCP plate fixation.

\section{Material and Methods}

The present study was including 60 patients of fracture of tibia who were be admitted in outdoor/emergency in the department of orthopaedics over a period of 2016-2017 in Katihar Medical College. 
Type of study: Prospective study

Inclusion Criteria

Patients with tibial diaphyseal fracture fulfilling the following criteria:

1 Tibial diaphyseal fracture .

2 Skin condition of the operative field Normal.

3 Patients and Party agreeing to have a surgery (after counseling).

4 No neurological deficit.

\section{Exclusion Criteria are as follows :}

1. Tibial mal-alignment and shortening.

2. Range of knee motion and extensor lag.

3. Range of ankle motion.

4. Foot Motion.

5. Pain in limb.

6. Swelling.

Duration of the study: $2016-2018$

Methods: A sequence of methods to be used during this study are as follows:

\section{Selection of cases.}

Based on Medical History ( Name, Age , Sex , History with duration of pain and tenderness, history of trauma, history of any pathology etc.)

Examination of diaphyseal tibial fracture: (Gustillo \& Anderson method)

To examine attitude, deformity, swelling, tenderness etc.

\section{Relevant laboratory investigation.}

Complete Blood count, Haemoglobin estimation, Fasting \& Post Prandial Blood Sugar, Blood Urea, Serum Creatinine, bleeding Time, Clotting Time, HIV, HBsAg, Anti HCV etc.

\section{Radiological Study}

Plane X-ray of Knee with Ankle of Affected Limb (AP \& Lat view)

All the patients selected will then be operated and followed-up after 3 weeks, 5 weeks for at least 6 month with clinical and radiological assessment at each visit. In all the cases a preoperative and postoperative neurological charts will be maintained with regular assessment for proper postoperative recovery assessment.

Implants: Universal Interamedullary Interlocking Nail DCP Plate

\section{Inclusion Criteria}

1. Diaphyseal fracture of tibia

2. Adults (after closure of epiphysis)

3. Duration of fracture less than 4 weeks

\section{Exclusion Criteria}

1. Badly Contaminated / Comminuted compound fractures

2. Patient medically unfit for surgery

\section{Observations}

The present study included 60 cases of fracture shaft of tibia admitted in department of Orthopedics, katihar medical college, katihar.

After proper resuscitation and splintage closed and grade 1 compound fractures of tibia were selected and fixed either with $4.5 \mathrm{~mm}$ DCP or interlock nailing, 30 patients each were treated by DCP and interlock nail. The following observations were made.

Table 1 Distribution of Patients According to Age

\begin{tabular}{|l|c|c|c|c|c|}
\hline $\begin{array}{l}\text { Age Group } \\
\text { (in years) }\end{array}$ & DCP & \multicolumn{2}{|c|}{ I/L Nail } & Total of \% age \\
\hline & No. of Patients & $\%$ age & No. of Patients & $\%$ age & \\
\hline $1-20$ & 3 & 5 & 6 & 10 & 15 \\
\hline $21-30$ & 10 & 16.67 & 10 & 16.67 & 33.33 \\
\hline $31-40$ & 8 & 13.33 & 10 & 16.67 & 30 \\
\hline $41-50$ & 5 & 8.33 & 3 & 5 & 13.33 \\
\hline $51-60$ & 3 & 5 & 1 & 1.67 & 6.67 \\
\hline $61-70$ & 1 & 1.67 & - & - & 1.67 \\
\hline Total & 30 & 50 & 30 & 50 & 100 \\
\hline
\end{tabular}

Age of patients ranged from 18 to 63 years. Maximum number of patients was in $2^{\text {rd }}$ and $3^{\text {th }}$ decade $(63.33 \%)$. Only 5 patients were above the age of 50 years. The age distribution in both groups was similar. 
Table 2 Sex Incidence

\begin{tabular}{|l|c|c|c|c|c|}
\hline $\begin{array}{l}\text { Age group } \\
\text { (in yrs) }\end{array}$ & \multicolumn{2}{|c|}{ DCP } & \multicolumn{2}{c|}{ I/L Nail } & Total of \% age \\
\hline & No. of Patients & $\%$ age & No. of Patients & $\%$ age & \\
\hline Male & 23 & 38.33 & 26 & 43.33 & 81.66 \\
Female & 7 & 11.67 & 4 & 6.67 & 18.34 \\
Total & 30 & 50 & 30 & 50 & 100 \\
\hline
\end{tabular}

The males outnumbered the females with 49 males and 11 females. Sex distribution in both groups was similar 23 males and 7 females in DCP group and 26 males and 4 females in interlock group.

Table 3 Mode of Injury

\begin{tabular}{|l|c|c|}
\hline Mode of injury & $\begin{array}{c}\text { No. of } \\
\text { Patients }\end{array}$ & $\begin{array}{c}\% \\
\text { age }\end{array}$ \\
\hline Road Side Accident & 53 & 88.33 \\
\hline Fall from height & 3 & 5 \\
\hline Fall of heavy weight & 1 & 1.67 \\
\hline Assault & 3 & 5 \\
\hline Total & 60 & 100 \\
\hline
\end{tabular}

As indicated in above table, in $88.33 \%$ of the patients the mode of injury was high energy trauma due to road side accidents. However fall from height, fall of heavy weight and assault also accounted for some of these fractures.
Table 4 Side Involvement

\begin{tabular}{|l|c|c|}
\hline Side & No. of Patients & $\%$ age \\
\hline Right & 32 & 53.33 \\
\hline Left & 28 & 46.67 \\
\hline Total & 60 & 100 \\
\hline
\end{tabular}

Fractures of both legs were seen on the right side in $53.33 \%$ of patients whereas left side was involved in $46.67 \%$ of cases.

Table 5 Status of Soft Tissue

\begin{tabular}{|l|c|c|}
\hline Status & No. of Patients & $\%$ age \\
\hline Closed & 45 & 75 \\
\hline Open Grade 1 & 15 & 25 \\
\hline Total & 60 & 100 \\
\hline
\end{tabular}

$45(75 \%)$ fractures were closed but $15(25 \%)$ open fractures indicate high frequency of open fractures associated with tibial fractures. Out of the 15 open fractures, 12 were fixed by DCP whereas in 3 of these interlocking was done.

Table 6 Type of Fracture

\begin{tabular}{|l|c|c|c|c|c|}
\hline \multirow{2}{*}{ Type of Fracture } & \multicolumn{2}{|c|}{ LCDCP } & \multicolumn{2}{c|}{ I/L Nail } & \multirow{2}{*}{ Total of \% age } \\
\cline { 2 - 5 } & No. of Patients & $\%$ age & No. of Patients & $\%$ age & \\
\hline Transverse & 13 & 21.67 & 18 & 30 & 51.67 \\
\hline Oblique & 14 & 23.33 & 9 & 15 & 38.33 \\
\hline Communited & 3 & 5 & 1 & 1.67 & 6.67 \\
\hline Segmental & 0 & 0 & 2 & 3.33 & 3.33 \\
\hline Total & 30 & 50 & 30 & 50 & 100 \\
\hline
\end{tabular}

Most of the fractures were either transverse or oblique, a small percentage were of comminuted or segmental type. Most of transverse fractures (18) were fixed by interlock nailing, most of the oblique (14) and comminuted (3) fractures were treated by DCP. Both the segmental fractures were internally fixed by interlock nailing.

\section{Results}

The results are assessed on the basis of Alho and Ekeland criteria's (Clinical Orthopaedics (231), 205-15 1988). ${ }^{92}$

This, criteria considers six aspects:

1) Tibial mal-alignment and shortening

2) Range of knee motion and extensor lag

3) Range of ankle motion

4) Foot Motion

5) Pain in limb

6) Swelling 


\begin{tabular}{|l|c|c|c|c|}
\hline \multirow{2}{*}{ Criteria } & Grade 1 & Grade 2 & Grade 3 & Grade 4 \\
\cline { 2 - 5 } & Excellent & Good & Fair & Poor \\
\hline A.Tibial malalignment and Varus/Valgus & \multicolumn{5}{|l|}{} \\
\hline (Degrees) & $2.5^{\circ}$ & $5^{\circ}$ & $10^{\circ}$ & $>10^{\circ}$ \\
\hline Shortening (cm) & 1 & 2 & 3 & $>3$ \\
\hline B. Range of knee motion & $>120$ & 120 & 90 & $<90$ \\
\hline Flexion & $<10^{\circ}$ & $10^{\circ}$ & $15^{\circ}$ & $>15^{\circ}$ \\
\hline Extension Defects & $>20^{\circ}$ & $20^{\circ}$ & $10^{\circ}$ & $<10^{\circ}$ \\
\hline C. Range of ankle motion & $>30^{\circ}$ & $30^{\circ}$ & $20^{\circ}$ & $<20^{\circ}$ \\
\hline Dorsiflexion & $5 / 5$ & $2 / 3$ & $1 / 3$ & $<1 / 3^{\prime}$ \\
\hline Planterflexion & None & Sporadic & Significant & Severe \\
\hline D. Foot motion (as compared to normal) & None & Minor & Significant & Severe \\
\hline E. Pain in the Limb &
\end{tabular}

Table 21 Results as per Criteria

\begin{tabular}{|l|c|c|c|c|c|c|}
\hline \multirow{2}{*}{ Results } & \multicolumn{2}{|c|}{ DCP } & \multicolumn{2}{c|}{ Interlock } & \multicolumn{2}{c|}{ Total } \\
\cline { 2 - 7 } & No. of cases & $\%$ age & No. of cases & $\%$ age & No. of cases & $\%$ age \\
\hline Excellent & 10 & 16.67 & 15 & 25 & 25 & 41.67 \\
\hline Good & 15 & 25 & 14 & 23.33 & 29 & 48.33 \\
\hline Fair & 5 & 8.33 & 1 & 1.67 & 6 & 10 \\
\hline Poor & - & - & - & - & & \\
\hline Total & 30 & 50 & 30 & 50 & 60 & 100 \\
\hline
\end{tabular}

In the present study, $90 \%$ patients had good to excellent results with $10 \%$ having fair results and no poor results. In DCP group there were 10 excellent, 15 good and 5 fair results whereas in interlock nailing group 15 patients had excellent, 14 patients had good results and 1 patient showed fair result.

\section{Discussion}

Fractures of the tibial shaft continue to be a common orthopaedic problem and significant difference of opinion persists regarding the choice of modalities of treatment. Various treatments have been suggested by different surgeons for fractures of the tibial diaphysis. Over the decades pioneers for surgical as well as conservative management have mentioned the merits of their preferred method of treatment and the drawbacks of the other method.

Functions of the lower limb are dependent on the combination of stability and mobility. Most evaluations of the conservative results in the literature have emphasized fracture union. While authors advocating the surgical management noted the importance of motion of the lower limbs. With the advances made in the art of surgery, availability of better instrumentation and better understanding of biomechanical and biological fixation, achieving union with good is the goal of treatment, rather than merely achieving union alone.

The indications for operative and non- operative treatment tibial shaft fractures have not been well defined. The amount of malalignment and shortening considered acceptable also controversial. The prognosis of tibial shaft fractures not only depends upon mode of fixation used but is also influenced by many variable such as comminution, initial displacement, level of fracture, status of fibula, whether the injury was open or closed and the patient characteristics.

The non operative methods of treatment of tibial shaft shaft fractures do not carry the risk of infection but axial and rotational malalignments and shortening leads to significant deformity and altered leading characteristics which lead to post traumatic arthritis.

Closed nailing aims at avoiding periosteal stripping while maintain reduction while the fracture heals by peripheral callus bridging. Closed nailing is the most biological way of treating the fracture shaft tibia.

Open reduction and internal fixation with plates and screws provide a rigid fixation and anatomical alignment. This method is an excellent method for 
the treatment of tibial malunion and non-union, as anatomical reduction is achieved and the fracture is sufficiently exposed so that bone ends may be freshed and bone graft added. This technique has an advantage over the intramedunary nailing in the patients who had external fixators, since it avoids the pin tracts (Wiss, 1986) ${ }^{84}$

\section{Summary}

The present study consisted of 60 patients with fracture shaft of tibia treated at Katihar medical college katihar, Of these 30 patients were treated by DCP and 30 patients with Interlock nailing and results were compared.

The age of patients ranged from 18-63 years with mean age of 34.07 years. The mean age in DCP group was 36.3 years and of interlock nailing group was 31.87 years.

Majority of patients (81.67\%) were males.

Road side accidents accounted for $88.33 \%$ of cases. Fall from height, fall of heavy weight and assault were other contributing factors.

Both sides were almost equally involved.

$75 \%$ patients had closed fractures and $25 \%$ had open grade 1 fractures.

$30 \%$ of the patients had associated injuries.

Autogenous cancellous bone grafting was done in eight cases.

Dynamization was done in three cases of interlock nailing.

Both the modalities lead to union DCP on an average of 17.93 weeks and interlocked nailing with average 16.13 weeks.

The operative time for DCP is lesser than that for interlocked nailing.

Interlocked nailing as compared to DCP is a more technically demanding procedure with intraoperative problem mainly regarding distal locking.

Interlocked nailing allows earlier weight bearing as compared to DCP leading to earlier return to employment and lesser knee and ankle stiffness.

Mild knee pain can be seen in interlocked nailing.

Skin necrosis in a problem with DCP but can be minimized by anterolateral plate placement for proximal and careful handling of tissues.

\section{Conclusion}

We conclude that DCP is a better mode of fixation for proximal and distal tibial facture and interlock nailing is ideal implant in diaphysial and segmental fractures.

\section{Bibliography}

1. Alho A Ekeland A, Stromsoe $\mathrm{K}$ et al. Nonunion of tibial shaft fractures treated with locked intramedullary nailing without bone grafting. J Trauma 1993;34(1):62-67

2. Alho A Ekeland A, Stromsone K et al. Locked intramedullary nailing for displaced tibial shaft fractures. J Bone \& Joint Surg 1990;72(5):805-809

3. Allgower M. Clinical experience with a new compression plate (DCP). Acta Orthop Scand Suppl 1969;125:45-61

4. Anderson LD, Hutchins WC, Wright Pe et al. Fracture of the tibia and fibula treated by casts and transfixing pins. J clin orthop 1974;105:179.

5. Behren F, Searles K. External fixation of tibia: Basic evaluation and prospective evaluation. J bone and joint 1996,68B:24654

6. Bhandari M, Kulkarni AV, Khera V et al. A comparison of reamed intramedullary nailing and plating of lower extremity fractures in patients with concomitant head injury. AAOS 67th annual meeting 2000.

7. Bhandari M, Tornetta P 3rd, Sprague S et al. Predictors of reoperation following operative management of fractures of the tibial shaft. J Orthop Trauma 2003;17(5): 353-61

8. Bintcliffe IW, Scott WA, Vickers RH. The case for an open approach to tibial nailing. Injury 1984;15(6)407-10

9. Bone LB, Daniel Sucato, Philip M Stegemann et al. Displaced isolated fractures of the tibial shaft with either a cast or intramedullary nailing. J Bone and Joint Surgery 1997;79(9):1336-1341. 